\title{
Lutowanie twarde w wybranych zastosowaniach w produkcji lotniczej
}

\author{
Brazing selected processes in aviation industry
}

\section{Streszczenie}

W artykule przedstawiono problematykę lutowania twardego w próżni cienkościennych elementów układów rozdziału powietrza na przykładzie instalacji do samolotów Airbus A318. Opisano podstawowe problemy występujące w procesach montażu i lutowania piecowego poszczególnych elementów instalacji.

Słowa kluczowe: lutowanie wysokotemperaturowe; lut BNi-2; lutowanie stopu INCONEL 600

\section{Abstract}

The paper describes the problems of high temperature brazing in vacuum of thin-walled air management systems based on example of air installations for Airbus A318. The basic problems occurring in assembling and high temperature furnace brazing process of the installations have been described.

Keywords: high temperature brazing; BNi-2 brazing filler metal; brazing of INCONEL 600

\section{Wstęp}

Lutowanie twarde, zwłaszcza lutowanie wysokotemperaturowe w próżni, jest charakterystycznym procesem specjalnym w przemyśle lotniczym. Technologia ta występuje w przeważającej części w produkcji silników lotniczych w obszarach, takich jak komory spalania, aparaty kierujące, łopatki turbiny, przewody rurowe. Wszędzie tam, gdzie wymagana jest precyzja połączeń poszczególnych elementów, odpowiednia wytrzymałość tych połączeń zarówno temperaturowa, jak i mechaniczna, szerokie zastosowanie znajduje proces lutowania wysokotemperaturowego w próżni i w atmosferach kontrolowanych. Bezsprzeczną zaletą tej technologii jest minimalny wpływ na deformację cieplną lutowanych zespołów, jak i możliwość lutowania w połączeniu z obróbką cieplną. W niniejszym artykule przedstawiono obszar zastosowań technologii lutowania w przemyśle lotniczym, w systemach rozdziału powietrza wykorzystywanych we współpracy z silnikiem lotniczym, jak i w kabinie pasażerskiej jako tzw. systemach podtrzymywania życia.

\section{Opis zagadnienia}

Systemy rozdziału powietrza w przeważającym stopniu budowane są w oparciu o stopy na bazie niklu, tzw. superstopy, najczęściej typu INCONEL 600. Są one stosowane w postaci cienkościennych blach powodujących, że cały zespół instalacji ma stosunkowo niewielką masę, co stanowi jeden z najważniejszych czynników w budowie systemów i instalacji lotniczych. Zastosowanie spawania metodą TIG, często ogranicza się do obszarów lub fragmentów insta- lacji i poszczególnych jej komponentów, gdzie deformacje występujące w procesie spawania są w pewnych uzasadnionych granicach akceptowalne. Natomiast wszędzie tam, gdzie deformacje takie są nie do przyjęcia przez wymogi technologiczno- jakościowe, oraz wszędzie tam, gdzie dostęp urządzeń spawalniczych (głowic spawalniczych) do krytycznych miejsc w zespole spawanym jest bardzo utrudniony lub wręcz niemożliwy - swoje zastosowanie znajduje proces lutowania twardego, głównie lutowanie piecowe.

Tablica I. Podstawowe oznaczenia normalizacyjne i nazwy handlo-

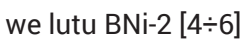

Table I. Basic standardization and trade markings of BNi-2 filler metal $[4 \div 6]$

\begin{tabular}{|c|c|}
\hline AWS A5.8 & BNi-2 \\
\hline AMS & 4777 \\
\hline ES EN 1044 & NI 102 \\
\hline DIN 8513 & L-Ni2 \\
\hline Handy\&Harman & Hi-Temp 820 \\
\hline Nicrobraz & LM \\
\hline General Electric & B50TF204 \\
\hline Allied Signal & EMS 54752-II / 94777 \\
\hline Rolls Royce & MSRP 9500/97 \\
\hline
\end{tabular}

Mgr inż. Jacek Baranowski - Bodycote Polska Sp. z o.o., Zakład w Rzeszowie.

Autor korespondencyjny/Corresponding author. jacek.baranowski@bodycote.com 
Niemal we wszystkich aplikacjach lutowania piecowego w produkcji systemów rozdziału powietrza wykorzystuje się najczęściej popularny stop lutowniczy BNi-2 na osnowie niklu, wg AMS4777. Poszczególne przykłady elementów instalacji rozdziału powietrza pochodzą wyłącznie z własnych doświadczeń produkcyjnych autora.

W tablicach I, II i III podano charakterystykę jednego z najpopularniejszych stopów lutowniczych stosowanych w połączeniach elementów instalacji lotniczych, natomiast w tabeli IV zamieszczono skład chemiczny stopu niklu Inconel 600.

Tablica II. Skład chemiczny lutu BNi-2 w \% wag. [4,5]

Table II. Chemical composition of BFM BNi-2 \% of mass $[4,5]$

\begin{tabular}{|c|c|c|c|c|c|c|}
\hline $\mathbf{N i}$ & $\mathbf{C r}$ & $\mathbf{S i}$ & $\mathbf{B}$ & $\mathbf{F e}$ & $\mathbf{C}$ & $\mathbf{P}$ \\
\hline reszta & $6,0-8,0$ & $4,0-5,0$ & $2,75-3,50$ & $2,5-3,5$ & $\begin{array}{c}0,06 \\
\max \end{array}$ & $\begin{array}{c}0,02 \\
\max \end{array}$ \\
\hline
\end{tabular}

Tablica III. Podstawowe właściwości lutu BNi-2 [6]

Table III. Basic properties of BNI-2 [6]

\begin{tabular}{|c|c|c|c|}
\hline $\begin{array}{c}\text { Solidus } \\
{\left[{ }^{\circ} \mathrm{C}\right]}\end{array}$ & $\begin{array}{c}\text { Likwidus } \\
{\left[{ }^{\circ} \mathrm{C}\right]}\end{array}$ & $\begin{array}{c}\text { Zakres } \\
\text { temperatury } \\
\text { lutowania } \\
{\left[{ }^{\circ} \mathrm{C}\right]}\end{array}$ & $\begin{array}{c}\text { Zalecana } \\
\text { temperatura } \\
\text { lutowania } \\
{\left[{ }^{\circ} \mathbf{C}\right]}\end{array}$ \\
\hline 970 & 1000 & $1010-1175$ & 1065 \\
\hline
\end{tabular}

Tablica IV. Skład chemiczny stopu INCONEL 600 [7]

Table IV. Chemical composition of INCONEL 600 [7]

\begin{tabular}{|c|c|c|c|c|}
\hline \multirow{2}{*}{ Inconel } & \multicolumn{4}{|c|}{ Skład chemiczny, \% wag. } \\
\cline { 2 - 5 } & $\mathbf{N i}$ & $\mathbf{C r}$ & $\mathbf{F e}$ & $\mathbf{M n}$ \\
\hline 600 & 72,0 & $14,0-17,0$ & $6,0-10,0$ & 1,0 \\
\hline \multirow{3}{*}{ Inconel } & \multicolumn{4}{|c|}{ Skład chemiczny, \% wag. } \\
\cline { 2 - 5 } & $\mathbf{C u}$ & Si & $\mathbf{C}$ & $\mathbf{S}$ \\
\hline 600 & 0,5 & 0,5 & 0,15 & 0,015 \\
\hline
\end{tabular}

\section{Wloty do instalacji rozdziału powietrza dla samolotów typu AIRBUS A318}

Pomimo, że lutowanie próżniowe wysokotemperaturowe to właściwie proces standardowy i typowy dla przemysłu lotniczego, należy zachować odpowiednie warunki w montażu poszczególnych części lub aplikacji materiału lutowniczego. Na poszczególne fazy całego procesu składają się [3]:

- mycie i odtłuszczanie części w alkalicznych roztworach wodnych (z odpowiednimi zatwierdzeniami jakościowymi),

- odtłuszczanie w acetonie,

- montaż i sczepianie metodą zgrzewania oporowego do lutowania (tzw. tack welding),

- kontrola szerokości szczeliny lutowniczej, aplikowanie materiału lutowniczego, głównie w postaci pasty za pomocą dyspenserów,

- zabezpieczanie obszarów, gdzie niepożądana jest obecność stopionego lutu za pomocą past STOP-OFF,

- wykonanie właściwego procesu lutowania piecowego,

- kontrola wykonanych połączeń lutowanych.

Na rysunku 1 pokazano schemat zespołu wlotu powietrza, a na rysunku 2 oraz 3 pokazano miejsca dozowania pasty lutowniczej.

Przerywaną linią zaznaczono typowe miejsca pokrycia pasty STOPP-OFF zapobiegającej nadmiernemu, niekontrolowanemu wypływowi lutu podczas cyklu lutowania piecowego.

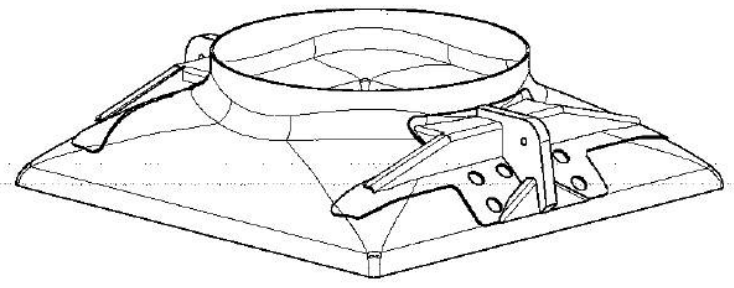

Rys. 1. Poglądowy schemat zespołu wlotu powietrza do instalacji rozdziału powietrza w samolocie Airbus A318 [1]

Fig. 1. Dratf scheme of air intake of air management system for Airbus $A 318$ [1]

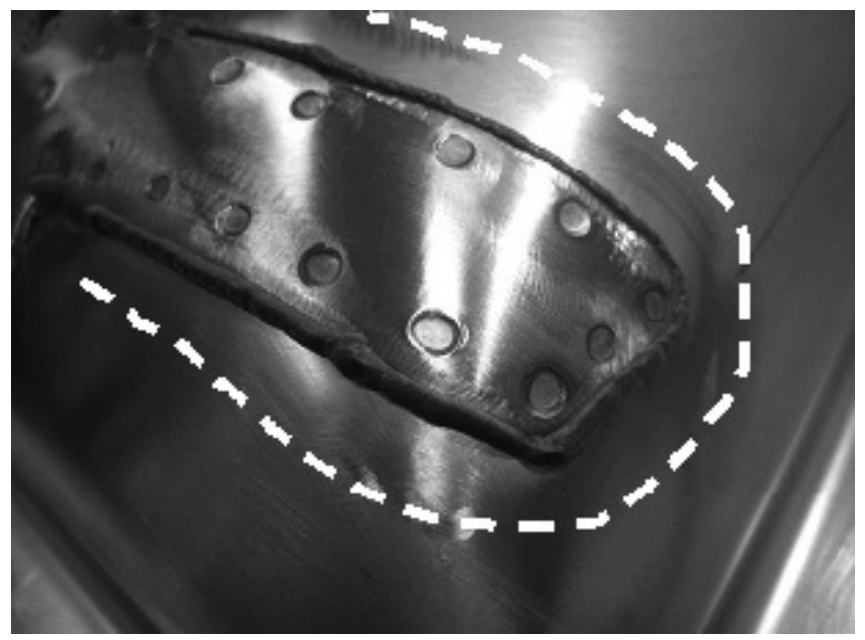

Rys. 2. Szczegóły aplikowania pasty lutowniczej BNi-2 na wspornikach [1]

Fig. 2. Details of application of BNi-2 brazing filler metal on brackets [1]

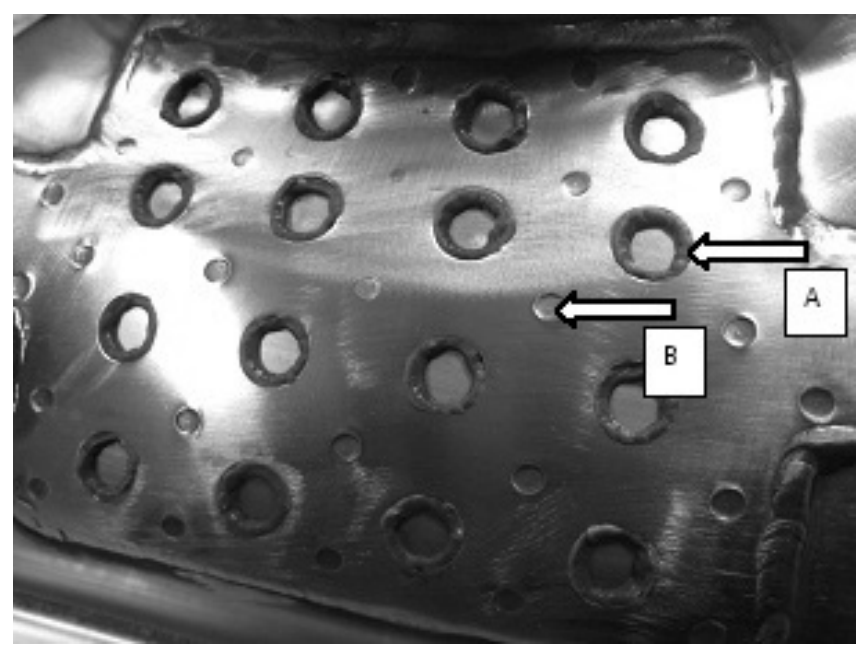

Rys. 3. Szczegóły aplikowania pasty lutowniczej BNi-2 na części centralnej wspornika (A). Na zdjęciu widoczne są również punkty zgrzewania oporowego (B) [1]

Fig. 3. Details of application of BNi-2 brazing filler metal on central area of bracket (A) [1] and points of tack welding as well (B) [1]

Bardzo ważnym czynnikiem przy aplikowaniu pasty lutowniczej jest stała i niezmienna ilość pasty umieszczana za pomocą sterowanego automatycznie aplikatora w poszczególnych miejscach. Na rysunkach $4 \div 7$ pokazano przykłady kontrolowanych połączeń lutowanych w zespole wlotu powietrza.

W procesie kontroli po lutowaniu piecowym, oprócz sprawdzania i weryfikacji samego procesu obróbki cieplnej (temperatura, czas, ciśnienie), kontroluje się jakość połączeń lutowanych, szczególnie wypełnienie szczelin lutowniczych w złączach. 


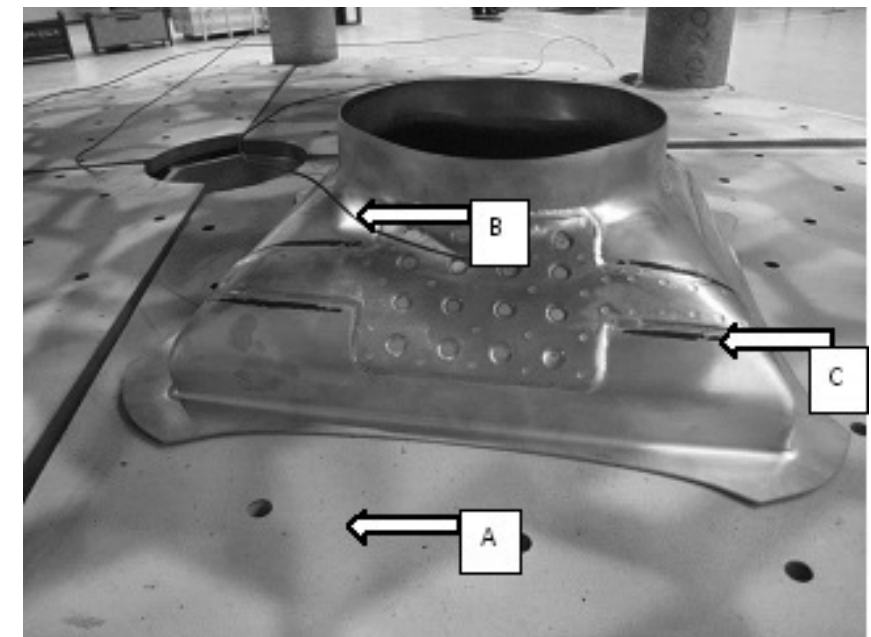

Rys. 4. Zespół wlotu powietrza bezpośrednio po cyklu piecowym. Widoczne odpowiednie płyty grafitowe pokryte ceramiką, zapobiegającą tworzeniu się eutektyki pomiędzy grafitem płyty a częścią lutowaną (A), termopary wsadowe typu N (B) oraz wypalona w procesie piecowym pasta typu STOP-OFF (C) [1]

Fig. 4. Air intake assembly after brazing furnace cycle. Visible graphite plates coated by ceramic to prevent eutectic melting phenomena (A), load thermocouples type $N(B)$ and burned off paste type STOP-OFF during the furnace cycle.(C) [1]

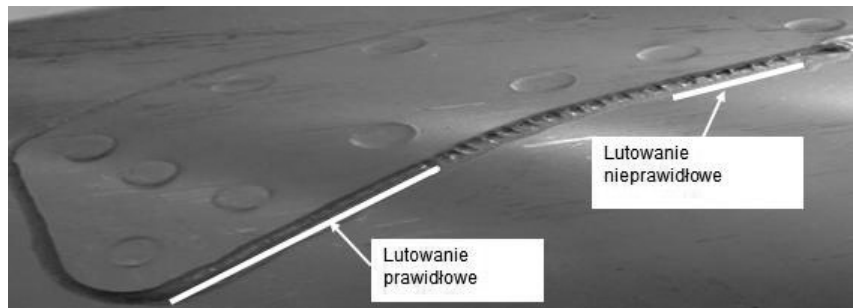

Rys. 5. Szczegóły kontroli połączeń lutowanych wsporników (przykłady prawidłowych i nieprawidłowych złączy) [1]

Fig. 5. Details of inspection of brazed joints of brackets (correct and incorrect examples) [1]

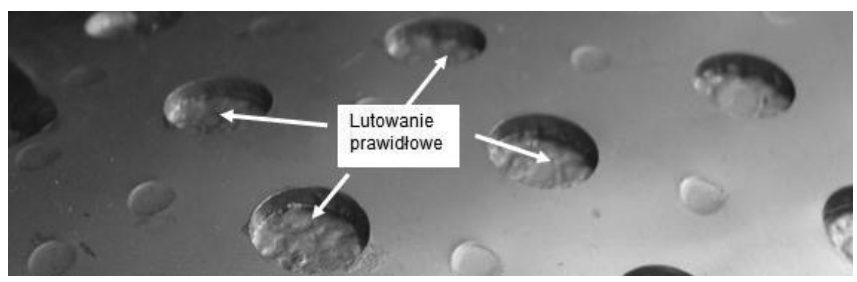

Rys. 6. Szczegóły kontroli połączeń lutowanych w części centralne wspornika (połączenia prawidłowe) [1]

Fig. 6. Details of inspection of brazed joints of central area of bracket (correct joints) [1]

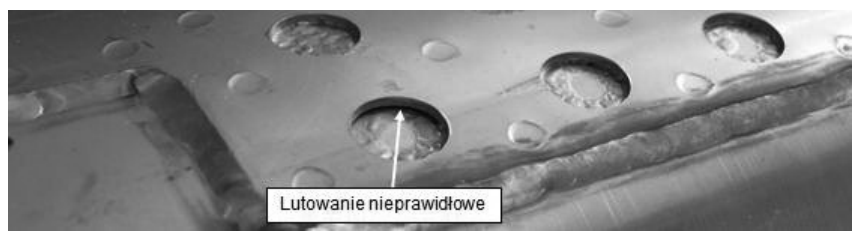

Rys. 7. Szczegóły kontroli połączeń lutowanych w części centralnej wspornika (połączenia nieprawidłowe) [1]

Fig. 7. Details of inspection of brazed joints of central area of bracket (incorrect joints) [1]

\section{Przykłady pozostałych elementów lutowanych}

Typowymi innymi elementami w tego typu instalacjach są chłodnice wstępne tzw. precooler'y, których połączenia lutowane pokazano na rysunkach $8 \div 11$.

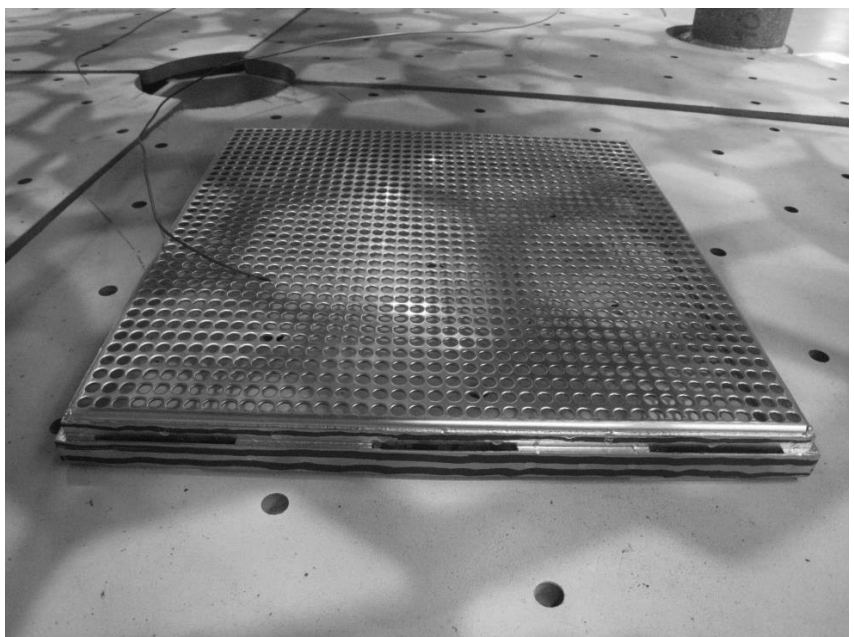

Rys. 8. Element wlotowy chłodnicy wstępnej po lutowaniu [1] Fig. 8. Air intake element of precooler after brazing cycle [1]

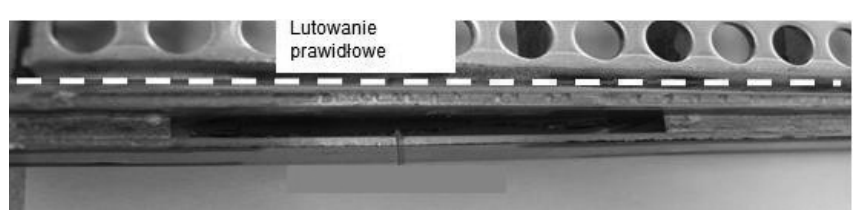

Rys. 9. Kontrola połączeń lutowanych (prawidłowych) na elemencie wlotowym do chłodnicy wstępnej [1]

Fig. 9. Inspection of brazed joints (correct) of air intake element of precooler [1]

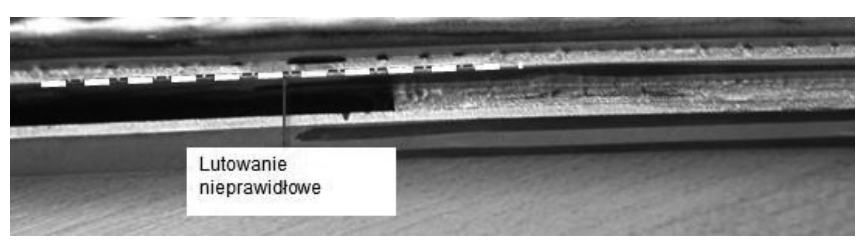

Rys. 10. Kontrola połączeń lutowanych (nieprawidłowych) na elemencie wlotowym do chłodnicy wstępnej [1]

Fig. 10. Inspection of brazed joints (incorrect) on air intake element of precooler [1]

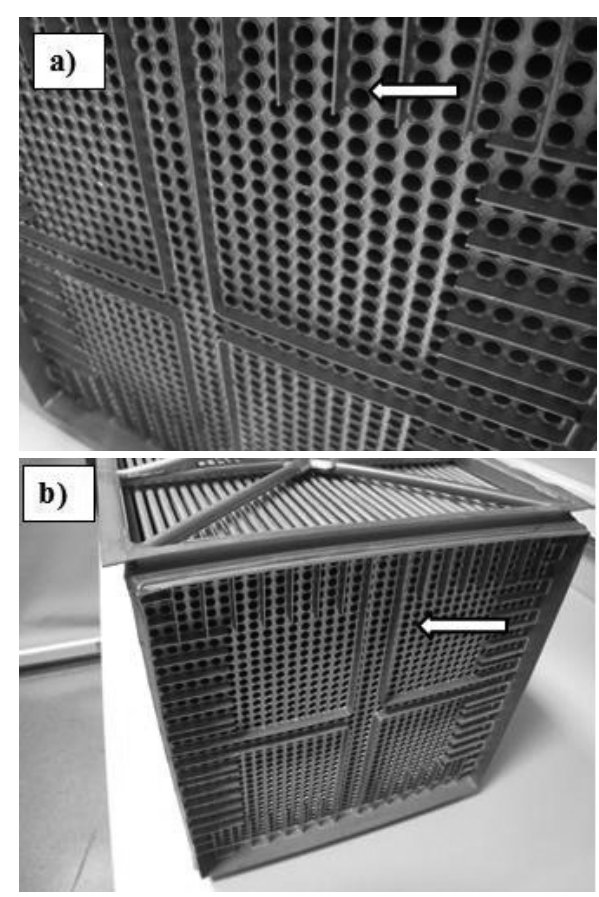

Rys. 10. Fragmenty właściwej chłodnicy wstępnej (precooler) instalacji rozdziału powietrza dla samolotu typu Airbus A318 (a, b). Widoczne wykonane połączenia lutowane rurek chłodnicy powietrznej [1] Fig. 10. Fragments of precooler of air management system for Airbus A318 (a, b). Visible brazed joints of tubes of precooler. [1] 


\section{Podsumowanie}

Pomimo, że opisane powyżej przykłady zastosowania lutowania twardego obejmują standardowy proces technologiczny [3], należy zwrócić uwagę na problemy technologiczno-jakościowe wynikające z zastosowanego materiału w postaci elementów cienkościennych, które podczas procesu obróbki cieplnej ulegają nieznacznej deformacji. Deformacja ta, ma jednak znaczący wpływ na niekontrolowane powiększanie się szerokości szczeliny lutowniczej, a co za tym idzie, niekontrolowane wypłynięcie lutu z obszaru lutowanego złącza. Aby zminimalizować to niekorzystne zjawisko należy stosować odpowiednie parametry lutowania tj. czas, prędkość nagrzewania i osiągania temperatury lutowania [1-3], a także stosowanie płyt grafitowych o minimalnej rozszerzalności cieplnej, które minimalizują stopień zdeformowania lutowanego zespołu. Nadal jednak technologia lutowania piecowego w próżni jest jedną z najważniejszych technik łączenia elementów instalacji stosowanych we wszelkiego typu konstrukcjach lotniczych.

\section{Literatura}

[1] Baranowski J.: Materiały własne z wdrożonych zastosowań lutowania próżniowego elementów układów rozdziału powietrza dla samolotów typu Airbus A318.

[2] Babul T., Baranowski J., Jakubowski J., Kopeć J., Kowalski S., Senkara J.: Lutowanie spoiwem na osnowie złota elementów układów zasilania sil-

ników lotniczych, VII Konferencja Naukowo-Techniczna, Olszanica, 2006.

[4] European Standard EN1044: Brazing. Filler metals, 1999.

[5] The Brazing Book, Lucas-Milhaupt, Inc. /Handy\&Harman, USA.

[6] Nicrobraz News, Wall Colmonoy Corporation, USA

[7] INCONEL alloy 600, Special Metals Corporation.

[3] Baranowski J., Kopeć J.: Lutowanie twarde części w przemyśle lotniczym, Przegląd Spawalnictwa, nr 8-9/2004, s. 57-59. 